\title{
CDISC SDTM Subject Characteristic Test Name Terminology
}

National Cancer Institute

\section{Source}

National Cancer Institute. CDISC SDTM Subject Characteristic Test Name Terminology. NCl Thesaurus. Code C103330.

The terminology that includes concepts relevant to the Clinical Data Interchange Standards Consortium (CDISC) Study Data Tabulation Model (SDT M) subject characteristics test names. 